\title{
An integrated livelihoods and well-being framework to understand northeastern Colorado ranchers' adaptive strategies
}

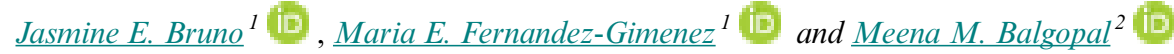

\begin{abstract}
As rangeland-based livestock systems experience social and ecological change, producers make increasingly complex livelihood decisions for improved or sustained well-being. Understanding these decisions requires more holistic frameworks that capture livelihood decision-making pathways and associated human well-being outcomes so that support systems reflect producers' needs. Here, we present the empirical foundation for an integrated livelihoods and well-being framework with the potential to address these gaps in the theory and practice of rangeland sustainability. We applied an iterative methodology using both inductive and deductive coding to analyze participant observation and semi-structured interviews with 32 rangeland-based livestock producers in northeastern Colorado, U.S. In our inductive coding, seven factors emerged as inputs for producers' livelihood strategies: financial (e.g., income), natural (e.g., land), social (e.g., community), human (e.g., labor), physical (e.g., infrastructure), political (e.g., access to policy makers), and cultural (e.g., way of life). Livestock producers described a dynamic process of interrelating these input factors to develop three primary livelihood strategies to avoid migration out of agriculture: contraction, expansion, and diversification of their operations. Through these livelihood strategies, producers increase or maintain their material (i.e., "what you have"), relational (i.e., "what you can do with what you have"), and subjective (i.e., "how you feel") well-being. Our results show that producers vary in access to cultural and political factors and emphasize the ubiquitous role of diversification as a livelihood strategy. Livestock producers' varying decisionmaking approaches emphasize the need for outreach and extension grounded in producers' lived experiences. This study offers a framework that researchers can use to integrate the emotional sphere into a social-ecological system framing (i.e., social-ecologicalemotional systems). Moreover, practitioners can apply this framework to design human-centered support systems for livestock producers in the western U.S. and beyond.
\end{abstract}

Key Words: agriculture; culture; grounded theory; ranching; rangelands; social-ecological systems

\section{INTRODUCTION}

Rangelands cover $40 \%$ of Earth's terrestrial surface and are critical to approximately one billion peoples' livelihoods, predominately through livestock production (Sayre et al. 2013). Both globally and in northeastern (NE) Colorado, U.S., rangelands, land with native vegetation dominated by grasses and shrubs, are undergoing linked social and ecological transitions and transformations (Brown and Thorpe 2008, Briske et al. 2015). In this context of social-ecological change, ranchers make increasingly complex livelihood decisions (Wilmer et al. 2020). Still, mirroring critiques in social-ecological systems (SESs) thinking more broadly, decision-making frameworks in agriculture have yet to deeply integrate critical social and emotional factors such as culture and well-being (Burton 2004, Prokopy et al. 2019, Bruno et al. 2020). In this study, we theorize the integration of the SESs sustainable livelihoods and well-being approaches by examining ranchers' subjective lived experiences.

SESs are complex, adaptive systems of interconnected social and ecological relationships, where human decisions and actions affect ecosystem functions and vice versa (Ostrom 2007). Inquiry into human-environment (Grossman 1977) and people-nature (Sayer 1979) relationships offered early thought on the interconnectedness between humans and the environment (Judkins et al. 2008). Subsequently, the emergence of resilience (Holling 1973) and systems thinking integrated concepts of feedback, boundaries, emergent properties, hierarchies, interaction, and self-organization (Steedman and Regier 1987, Turner et al. 1990, Liu et al. 2007, Meadows 2008). Yet, critiques of SES scholarship continue to emphasize the limited attention to culture, power, and agency, i.e., the ability to make decisions autonomously and creatively (Crane 2010, Coulthard 2012, Stojanovic et al. 2016, Schlüter et al. 2019, Elsawah et al. 2020). Although rangeland scientists, among others, have conceptually and empirically linked social and ecological processes on rangelands, large gaps remain in our understanding and account of the social and emotional elements of these complex systems (Ostrom 2009, Westley et al. 2011, 2013, Brunson 2012, Huntsinger and Oviedo 2014, Hruska et al. 2017).

These gaps often stem from the challenges of SESs research, such as struggles to match scales across the social and ecological spheres, which often result in an aggregated examination of the social (Elsawah et al. 2020). Although such simplifications in SESs models and frameworks can facilitate shared understanding, the resulting gaps in these tools are mirrored in the programs and policies they inform (Escalera-Reyes 2020). As a result, natural resources and rangeland-specific research and practice often overlook critical elements of subjective life, such as culture and well-being (Bruno et al. 2020). Thus, SES models and frameworks of culturally and place-based processes, e.g., individual and household decision making, must capture lived experiences at a higher resolution to better inform natural resources programming and policy.

We use qualitative data on livestock producers' lived experiences from two communities in NE Colorado to theorize the link between ranchers' livelihood decisions and their well-being. We

${ }^{1}$ Department of Forest and Rangeland Stewardship, Colorado State University, Fort Collins, Colorado, USA, ${ }^{2}$ Department of Biology, Colorado State University, Fort Collins, Colorado, USA 
apply our proposed framework to illustrate ranchers' prominent adaptive strategies, examining the feedbacks between livelihoods and well-being. We advance SES research and begin to address the gaps outlined above by presenting a social-ecologicalemotional framing, which researchers and practitioners can use to inform human-centered programming and policies in western U.S. rangelands and beyond.

\section{THEORETICAL FRAMEWORK}

We initiated this research with existing knowledge of and interest in adapting the sustainable livelihoods approach (SLA) to the context of NE Colorado. The focus on well-being emerged during the study and became a second critical framework for our data interpretation. Here, we propose that these two approaches complement each other. For instance, the SLA captures the complexity of decision pathways, but the current livelihoods framework fails to consider how the subjective emotional sphere influences decisions (and vice versa). Similarly, scholars and practitioners have yet to converge on how the social and ecological spheres affect well-being. We offer that framing well-being as both a driver and outcome of livelihood strategies (and vice versa) could advance both approaches.

\section{The sustainable livelihoods approach (SLA)}

As an alternative to "disciplinary reductionism" (Chambers and Conway 1992:3) and the exploitation of rural people and places, researchers and development practitioners in the 1990s aimed to position rural perspectives at the center of knowledge and innovation development (Solesbury 2003). Sustainable livelihoods were conceptualized and subsequently incorporated into the United Nations' Earth Summit 1992 (Perrings 1994). We follow Chambers and Conway's (1992:6) definition of livelihoods as: "the capabilities, assets (stores, resources, claims, and access) and activities required for a means of living." Inherent in this definition is the understanding that resilience, i.e., the ability to cope with and recover from shocks, and sustainability, i.e., benefits to the next generation, are critical aspects of livelihoods.

Researchers and practitioners have diagramed the livelihoods framework in a diversity of configurations with slight variations in the capabilities/assets/capitals represented. For example, the United Kingdom's Department for International Development (DFID) depicts livelihoods as a pentagon of the five interrelated capitals of financial (e.g., income), natural (e.g., land), and social (e.g., community), human (e.g., labor), and physical (e.g., infrastructure; Hussein 2002). The frame focuses on the impacts of macro-social and ecological dynamics on the micro-social scale (Binder et al. 2013). Aligned with the overarching critiques of SES theory, gaps remain in consideration of the social sphere, most notably the limited attention to culture, political factors, and self-identity. Although community-level frameworks, such as the community capitals framework, include consideration of culture and politics, these dimensions remain underexamined in individual and household-level decision-making frameworks (Emery and Flora 2006).

The overwhelming majority of livelihoods research has focused on Africa and Asia (e.g., Kydd et al. 2004). Yet, we suggest that the livelihoods framework is a potentially valuable approach to understand a diversity of SESs, including in the Global North. Coles and Scott (2009) provided a notable exception, applying the
SLA to examine farmers' and ranchers' livelihoods and adaptive strategies in southeastern Arizona, U.S. They found that producers' livelihood conceptualizations extended beyond economic factors, including their connections to land, community, and agricultural identities. Thus, participants' primary goal was the long-term viability of their farms and ranches, making them reluctant to adopt adaptive strategies they viewed as uncertain. Although Coles and Scott's (2009) livelihoods analysis offered insights into a specific population, they stopped short of constructing a framework with broader applications. The current SLA framework fails to capture the nuances of U.S. livestock producers' livelihood strategies. We posit that the SLA's lack of contextualization to the Global North contributes to the framework's limited use in the U.S. This research addresses this incompleteness by constructing an integrated livelihoods and well-being framework from $\mathrm{NE}$ Colorado livestock producers' lived experiences. Such contextspecific models offer applications in analogous systems and illuminate context-specific factors' effects in broader theory (Hong et al. 2014).

Last, previous research used the terms "assets" or "capitals" to refer to elements identified as having value by the participants. We argue that value can extend beyond monetization and that a diversity of valuation systems exists (Scholte et al. 2015, Jacobs et al. 2016). For many, factors such as family, faith systems, one's agency, morals, and ethics, a sense of belonging, and friends provide value that extends beyond what economic systems can capture or those elements of our lives that are "invaluable." To reflect this understanding, we refer to "factors," whether financial, social, or otherwise, that contribute to constructing one's livelihood. Also, we consider livelihoods sustainable only when the health of both people and the natural system are maintained or improved long term (Chambers 1992, 1995).

\section{The well-being framework}

The concept of well-being draws heavily from the field of human development while integrating concepts from diverse areas of study, such as livelihoods (McGregor and Sumner 2010). Although multiple well-being indices exist, conservation and development practitioners and researchers have begun to converge on shared well-being principles. This conceptualization of well-being that captures the multi-dimensional interplay of the material (i.e., "what you have"), relational (i.e., "what you can do with what you have"), and the subjective (i.e., "how you feel about what you have and what you can do") has gained momentum (McGregor and Sumner 2010, Beauchamp et al. 2018). For instance, within this framing, an individual's high wealth levels, i.e., material, and an inability to leverage this wealth to achieve their goals, i.e., relational and subjective, can result in low wellbeing overall.

Moreover, researchers increasingly acknowledge the effects of environmental management changes on human well-being, and vice versa (Agarwala et al. 2014, Topp et al. 2015, Fry et al. 2017). With an SESs framing, Armitage et al. (2012) modified McGregor's (2008) definition of human well-being as, "A state of being with others and the natural environment that arises where human needs are met, where individuals and groups can act meaningfully to pursue their goals, and where they are satisfied with their way of life." Dawson and Martin (2015) integrate well- 
Fig. 1. The study sites in northeastern Larimer County and northcentral Weld County, Colorado (ESRI 2011). The study area symbols indicate the average extent of participant agricultural landholdings.

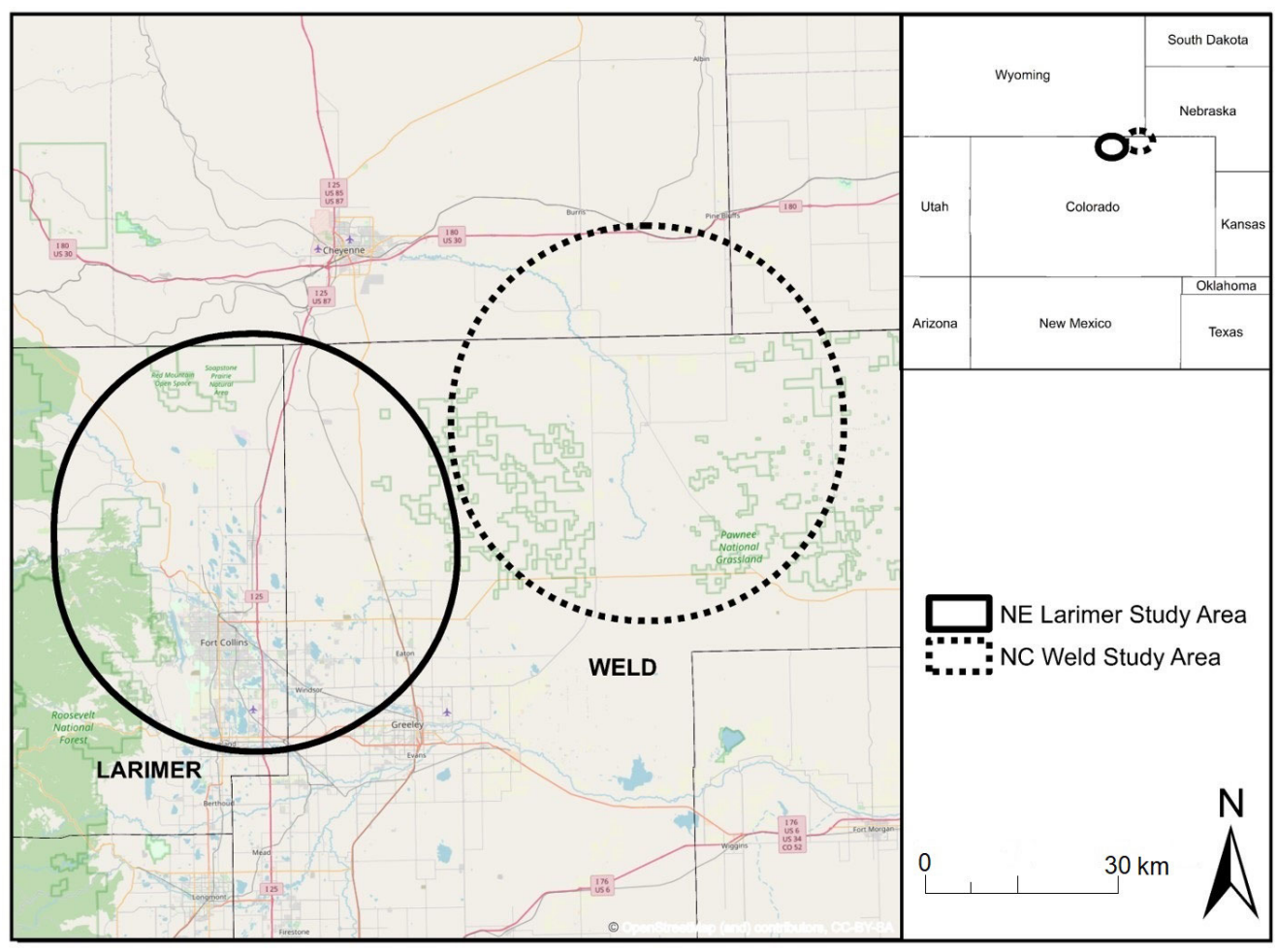

being into an ecosystem services analysis to overcome what they reference as social-ecological reductionism, or a failure to acknowledge multi-scale change, power, and the social sphere's complexity. Conceptualizations of well-being advance SESs thinking by acknowledging the differences in people's well-being, offering a more in-depth examination of the social sphere (McGregor and Sumner 2010). For instance, individuals' wellbeing goals, pathways to well-being, and capabilities to pursue well-being differ (McGregor and Sumner 2010). Beauchamp et al. (2018) examined this heterogeneity of well-being in three communities in Cambodia, identifying how unique land uses in each site influence peoples' well-being conceptualizations.

Despite the momentum of well-being in conservation and development work, much of the empirical well-being research in natural resources to date has positioned well-being as an outcome of human-environment interactions (Biedenweg et al. 2017, Beauchamp et al. 2018, Woodhouse and McCabe 2018). For instance, research programs consider how interventions can contribute to well-being improvements in human systems (Wongbusarakum et al. 2014). For example, the Puget Sound Partnership researchers, a coordinating body for the Puget Sound recovery in Washington, co-created and integrated well-being indicators into an ongoing recovery program (Biedenweg et al. 2017). However, research has less often considered well-being's role in initiating changes in human-environment reactions; our systems framing addresses this gap, examining how well-being outcomes feedback to livelihoods.

\section{STUDY AREAS}

NE Colorado provides the context for this study. We selected two sites to contextualize the framework within the region (Fig. 1). We defined the study area to include a site in NE Larimer County in the rapidly growing Front Range Urban Corridor (running north-south between Cheyenne, Wyoming and Pueblo, Colorado) and one more rural site in northcentral (NC) Weld County.

Both sites lie within the semiarid region of the central grasslands of North America. The shortgrass steppe dominates the eastern extent of the NE Larimer site, transitioning westward into midgrass prairie, shrublands, and ultimately forest in the foothills of the southern Rocky Mountains. The NC Weld site consists of shortgrass steppe punctuated by the iconic Pawnee Buttes (Milchunas et al. 1998). Following the forced removal of the Indigenous inhabitants in the late 19th century, the communities share livestock grazing histories on native vegetation, with cultivated land as the secondary land use (Lauenroth et al. 2008).

The two study sites experienced divergent development trajectories at the start of the 21 st century, however. In the Larimer study site, the population boomed $135.4 \%$ from 2000 to 2010 (U.S. Census Bureau 2000, 2010). Larimer County and associated cities strive to balance exurban growth with conservation goals (Resnik et al. 2006, York et al. 2011). In comparison, the NC Weld County study site experienced a $-10.5 \%$ change in population from 2000 to 2010 , and some neighboring communities were abandoned (U.S. Census Bureau 2000, 2010). 
Moreover, although agriculture has remained central to many Weld County towns, several communities are increasingly economically dominated by the oil and natural gas industry, including our study site (Davis 2012). We selected these two adjacent sites with divergent development trajectories to capture the diversity of agricultural communities in NE Colorado.

\section{METHODS}

\section{Methodology}

We used an iterative methodology informed by constructivist grounded theory (Charmaz 2006, 2008). Grounded theory is a systematic methodology that analyzes contextual data to integrate or develop broader theory (Guetterman et al. 2019). Our initial analysis began using inductive methods. Because constructivist methodology acknowledges a priori knowledge, as some themes emerged, we acknowledge the alignment of our initial themes with existing frameworks. Thus, we used a deductive approach to relate emergent themes with existing frameworks' terminology when relevant. Using inductive analysis allowed us to identify unexpected and novel themes that described participants' perceptions and how they construct a living or livelihood, and deductive analysis enabled us to relate our proposed framework to the existing literature. Our iterative methodology of both inductive (identifying patterns) and deductive analyses (understanding patterns) facilitated ongoing scrutiny of the data and interpretations. This study offers an early contribution to theory, and we encourage applications and adaptations to new sites and systems, advancing the generalizability of the proposed framework (Firestone 1993).

\section{Data collection}

The first author collected data through participant observation and 26 semi-structured interviews with 32 producers in the summer and fall of 2018 and 2019. (Fig. 2). We collected all data under Colorado State University human subjects Institutional Review Board protocol 040-19H. Participant observation is a means of observing daily life from the participants' standpoint (Goffman 1989, Sprague 2016). The first author engaged in participant observation on one participant's ranch for two weeks, conducting daily chores, recording field notes, and memoing throughout the experience. During participant observation, the first author met community gatekeepers who introduced her to research participants and invited her to introduce this study at a community meeting. The first author continued to participate in workdays on multiple operations throughout the study period.

All 32 interview participants identified agriculture as an occupation and reared livestock, including cattle, sheep, and goats (Table 1). Participants ranged in age from 37 to 90, including both first-generation and multi-generation producers. Although race and ethnicity are critical to experiences and social factors, we do not disclose participants' race and ethnicity to ensure anonymity. Participants' gender, ethnicity/race, and years on their current operation are representative of Colorado's agricultural population (USDA NASS 2017). Yet, participants' operation size by hectares is greater than the state average, which we posit is because of our focus on grazed livestock operations (USDA NASS 2017).
Fig. 2. Diagram of the iterative research process from which we derived an integration of the sustainable livelihoods approach (SLA) and well-being (WB) framework (adapted from Charmaz 2006).

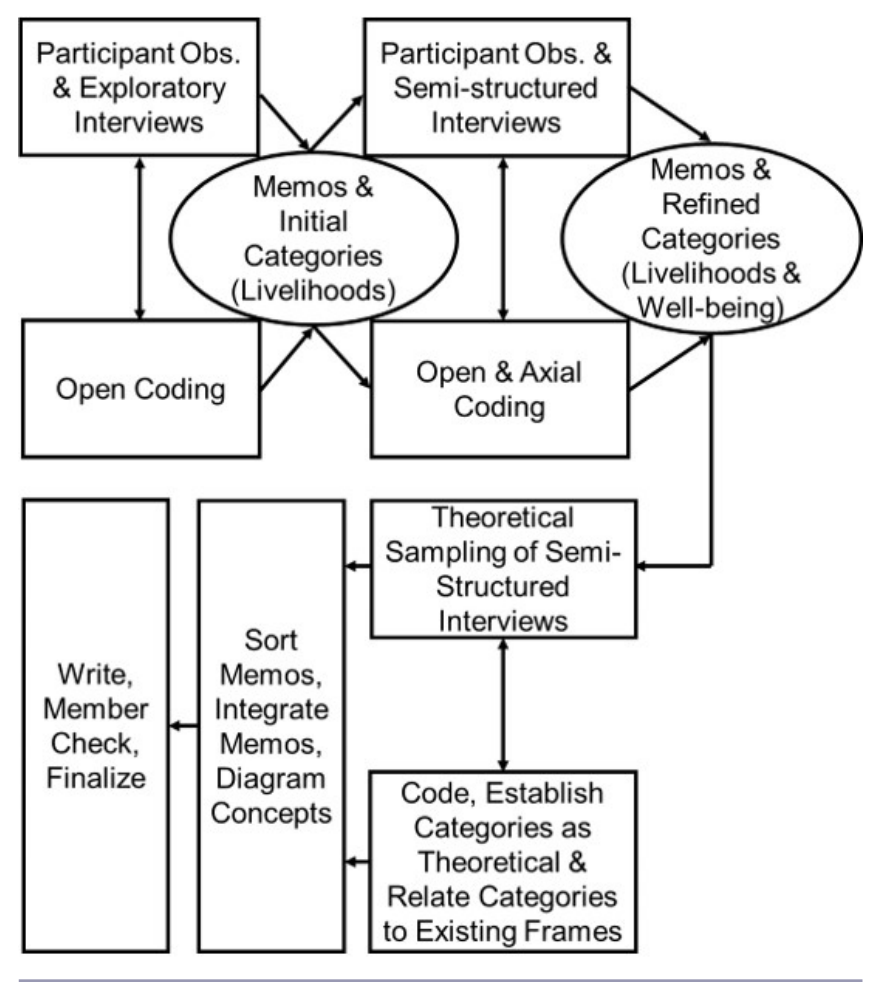

Table 1. Characteristics of interview participants.

\begin{tabular}{lc}
\hline \hline Characteristics & Participants $(\mathrm{n}=32)$ \\
\hline Gender & 13 \\
Female & 19 \\
Male & \\
& \\
Geography & 15 \\
Northeastern Larimer & 17 \\
Northcentral Weld & \\
Interview Mode & 20 \\
Individual & 12 \\
Couples & \\
& \\
Production Status & 5 \\
Retired & 27 \\
Active &
\end{tabular}

The first author conducted all interviews, with interviews averaging 100 minutes and often involving a tour of the operation. At the start of the research, we used snowball sampling or the recruitment of subjects by existing participants (Noy 2008). Our initial interviews were exploratory with prompts such as, "How did you become a rancher?" and "Can you walk me through your typical day?" As inductive data collection and analysis progressed, 
Table 2. Overview of the livelihood input factors, livelihood strategies, and well-being outcomes. Given our inductive approach, all components emerged from our data, and we subsequently explored their presence in the literature.

\begin{tabular}{|c|c|c|}
\hline Livelihood Input Factors & Livelihood Strategies & Well-being Outcomes \\
\hline $\begin{array}{l}\text { Financial: economic resources, e.g., savings, } \\
\text { investments, income, cattle, land, home equity } \\
\text { (Scoones 1998) }\end{array}$ & $\begin{array}{l}\text { Contraction: reduction of business activity and } \\
\text { operation scale, e.g., sale of animals or land }\end{array}$ & $\begin{array}{l}\text { Material: assets, income, ecosystem services, } \\
\text { health, and wealth (Armitage et al. 2012) }\end{array}$ \\
\hline $\begin{array}{l}\text { Natural: natural stocks that people can draw on, e. } \\
\text { g., land, forests, and water (Scoones 1998) }\end{array}$ & $\begin{array}{l}\text { Expansion: increase in economic activity and } \\
\text { growth of operation, e.g., purchase of animals or } \\
\text { land }\end{array}$ & $\begin{array}{l}\text { Relational: social resources and relationships that } \\
\text { contribute to identities and personal action, e.g., } \\
\text { social, political, or cultural (Armitage et al. 2012) }\end{array}$ \\
\hline $\begin{array}{l}\text { Social: social resources, e.g., family, community, } \\
\text { cooperatives, and grazing associations (Scoones } \\
\text { 1998) }\end{array}$ & $\begin{array}{l}\text { Diversification: variation of the range of products } \\
\text { or areas of operation either on-operation, e.g., } \\
\text { vertical integration within the beef sector and } \\
\text { conservation easements, or off-operation, e.g., a } \\
\text { family member's job in town }\end{array}$ & $\begin{array}{l}\text { Subjective: self-reported quality of life, } \\
\text { aspirations, and emotional health, e.g., happiness, } \\
\text { security, satisfaction, (Armitage et al. 2012) }\end{array}$ \\
\hline \multicolumn{3}{|l|}{$\begin{array}{l}\text { Human: individual attributes, e.g., work ethic, } \\
\text { knowledge, and physical capabilities (Scoones } \\
\text { 1998) }\end{array}$} \\
\hline \multicolumn{3}{|l|}{$\begin{array}{l}\text { Physical: human-made objects, e.g., infrastructure, } \\
\text { technology, tools (Serrat 2017) }\end{array}$} \\
\hline \multicolumn{3}{|l|}{$\begin{array}{l}\text { Political: access to power, organizations, or } \\
\text { individuals that influence governance and resource } \\
\text { management (Ribot and Peluso 2003, Flora et al. } \\
\text { 2004) }\end{array}$} \\
\hline $\begin{array}{l}\text { Cultural: way of life, heritage, and beliefs that } \\
\text { create shared meaning for a social group (Flora et } \\
\text { al. 2004, Pretty 2011) }\end{array}$ & & \\
\hline
\end{tabular}

we framed our semi-structured interview instrument around livelihoods. As the concept of well-being emerged, we modified the interview protocol to address well-being outcomes further (Appendix 1). We transitioned from snowball to theoretical sampling to support the emergence of theory, i.e., selecting participants to support theory development, (Coyne 1997, Breckenridge and Jones 2009).

\section{Data analysis and trustworthiness}

The first author coded the interviews and participant observation memos using the constant comparative method (Strauss and Corbin 1994, Charmaz 2006, 2008) in RQDA (Huang 2014, R Core Team 2019). Using inductive analysis, we explored what concepts were significant and frequent, then collapsed these into axial codes before determining how themes related to one another (Strauss and Corbin 1998, Charmaz 2006, 2008). We conducted theoretical memoing, clustering, and selective coding during subsequent analyses, during which we integrated preliminary findings into late-stage interviews to facilitate discussion with participants. The data collection cycle and analysis continued until we achieved categorical saturation, allowing us to construct our grounded theory (Saunders et al. 2018). In diagraming our integrated theory, we deductively drew parallels to naming conventions of existing frameworks when appropriate. For instance, we collapsed "on-operation labor" and "personal attributes" and deductively labeled the category "human factors" to align with existing conventions.

We applied Lincoln and Guba's (1986) criteria to ensure the trustworthiness of our analysis. The iterative, multi-method design facilitated prolonged engagement with participants, supporting understanding, trust, iterative questioning, and triangulation. Additionally, we maintained an audit trail with the first author engaged in reflective commentary through memoing and peer debriefing. We achieved theoretical saturation, seeking counterexamples throughout the analysis, and last, we presented the research findings to producers (member checking) and revised them when appropriate.

\section{FINDINGS}

We present our integrated framework and ground the components of the proposed framework in our data. Specifically, we share findings of the seven livelihood factors, i.e., financial, natural, social, human, physical, political, and cultural, and we outline well-being outcomes, i.e., material, relational, and subjective. We present livestock keepers' framing of the study sites' broader social and ecological context. And we employ our framework to illustrate the following three adaptive livelihood strategies, i.e., producer decision pathways in the face of change: contraction, expansion, and diversification (Table 2).

\section{Integrated SLA and well-being framework}

The emergent integrated SLA and well-being framework illustrates how livestock owners draw upon seven factors to assemble livelihood strategies for improved well-being (Fig. 3). The framework captures the influence of social and ecological change, e.g., drought and market downturns, on producers' livelihood factors and well-being. In turn, these changes drive livestock keepers to adapt their strategies to maintain or increase their well-being outcomes. Thus, effects on the livelihood factors flow through the system to influence the well-being outcomes and vice versa.

\section{The foundational livelihood factors (financial, natural, and social)}

Livestock keepers identified financial, natural, and social factors as foundational or essential to how they conceptualized their livelihoods. Participants recurringly emphasized the significance 
of these factors. Ranchers presented finances as foundational to the existence and future of their operation. For most, livestock is what "brings in the money, so you have to figure out a way to pay for everything with them" (R11). One Weld County couple identified financial strategies as differentiating rural, familyowned businesses from multinational companies like the meat processor JBS:

Fig. 3. The integrated sustainable livelihoods approach and well-being framework for northeastern Colorado livestock producers. Within the context of rapid social and ecological change, livestock producers interrelate these seven livelihood factors, i.e., financial, natural, social, human, physical, political, and cultural, to create strategies to sustain or improve their material, relational, and subjective well-being. Financial, natural, and social factors are represented in grey as foundational factors or those essential to how producers conceptualize their livelihoods. Feedback between well-being outcomes and livelihood factors facilitate cycles of accumulation, sustaining, or decline.

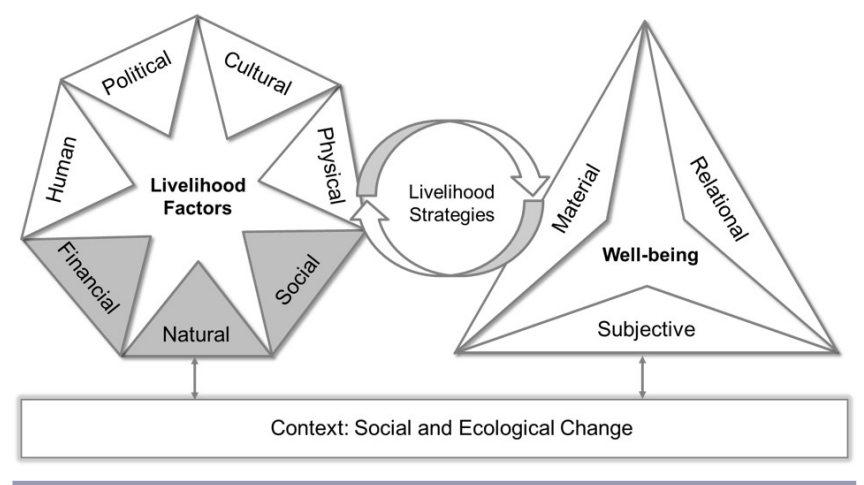

[Making money in the middle is] generally rural America's attitude, and then, JBS is a Brazilian owned company and purely a corporate-owned structure, and that is very, very money-driven. Of course, we are moneydriven too. That is the name of the game. You need to make money. It is the management in the middle that we really concentrate on. $(\mathrm{R} 1)$

The couple continued to articulate that rural U.S. producers deviate from multinational corporations' "cookbook formula." They clarified that "we try to make our strengths where their weaknesses are, and that has been our success" (R1). They perceived large companies as "volume" driven, while the money in rural America is made "on management" (R1). Wilmer et al. (2020) found that ranchers were "managing for the middle," or mitigating risk and variability by employing management practices that strike a balance between competing responsibilities. Similarly, we found that instead of focusing on a singular strategy, e.g., large cattle numbers, ranchers made a series of management decisions to balance their gains and losses across different factors, i.e., "management in the middle." Moreover, producers emphasized the centrality of the financial factor in supporting other aspects of their operations, such as relational well-being outcomes, e.g., "peace" among the members of the family business, and investment in the natural factor, e.g., invasive species management.
There is not always a clear distinction between financial and natural resources in U.S. farming and ranching (Vitiello and WolfPowers 2014). For example, private land or grazing privileges, e. g., public land grazing leases, can function as financial assets (and liabilities), often serving as collateral for annual operating loans. Our proposed framework recognizes this fluidity while also acknowledging the unique roles of natural and financial factors in shaping livelihood strategies and supporting well-being. One northeastern Larimer producer captured this need to balance the interplay between natural and financial factors:

It boils down to managing your limiting functions. And so, in general, when you look at it from a resource perspective, the limiting functions are soil, water, sun, and money... How do you manage all this stuff in a way that you can be a steward of your resources, utilizing them in a reasonable way, but also have the money to do so? (R10)

Despite participants' emphasis on strategies that cultivate balance, especially between financial gains and the longer term management of natural resources, they still experienced the vulnerability of natural resource-dependent livelihoods. Below, one rancher captured the inherent but tenuous relationship between nature and her well-being:

I am dependent upon whatever falls from the sky, so there are some years where we are in better shape than others because we had a wet year, etc. When it is a dry year, not only am I dry, but that means that hay is short. (R3)

Social factors are also foundational and interrelated with financial and natural elements, but participants stressed that their rural, agricultural communities are changing. In this context of change, some producers shared experiences of increased social factors, while other peoples' social resources had decreased. Aligned with this disparity of experiences, producers related ownership of scarce and high-value natural resources, such as oil, water, and land, to political and social factors that influence power dynamics. For example, one rancher stated, "Owning [water] gives some clout; you sell it, you lose the clout" (R8). Here, we draw upon Ribot and Peluso's (2003:154-155) framing of "access as bundles and webs of powers that enable actors to gain, control, and maintain access." Through this lens, the ownership of scarce water rights in the context of high urban and industrial demand for water in much of the western U.S. affords access to social and political factors, which in turn facilitate further access to power and resources. Yet, as SESs shift, the valuation of resources change, altering access and, in turn, social dynamics (Ribot and Peluso 2003).

Moreover, participants emphasized that as operators of familyowned ranching businesses, their businesses' and families' wellbeing interrelate with their communities' well-being. From shopping at the local grocery to ranchers working together to get through a drought, participants identified the survival of local economies as central to their communities' long-term futures and, in turn, their operations. One couple discussed how other local producers contribute to their operation, and therefore, they reciprocate support to enable the future of local business:

Our main source of income is cattle feeding, and our land is geared towards feed crops to support our feedlots, but all of our neighbors sell cattle to us. So, if they are 
experiencing a drought, we will move up our timeline on when we purchase our calves to when they are running out of feed. Or we will take some of our irrigated land and sell them some of our feed so that they can get through the drought times. A lot of that comes through the church because a lot of the people that we deal with go to the same churches. (R1)

Participants shared how strong community relationships through institutions such as schools, churches, and associations enable producers to support each other's adaptive capacity. Yet, despite the significance of social factors, one Weld County farmer shared the following:

During the last election, I've seen our country spread apart further than I'd ever seen in my life, and that really bothers me. And it was almost getting to the point that when you go to a social event, are you going to sit with a Democrat or are you going to sit with a Republican? Because [if] we sat with a Republican, the tension is a little bit higher than what it is if you sat with a Democrat. (R19)

Above, the farmer illuminated how county-level change has negatively affected his and other peoples' social factor, specifically their social networks (Cash et al. 2006).

\section{Human and physical factors}

Juxtaposed to the necessity of financial, natural, and social factors in establishing and maintaining livestock operations, participants presented human and physical factors as those used to grow their operations further. In many cases, livestock keepers discussed human and physical factors as substitutes for one another. For instance, changes in technology (a physical factor) have reduced labor needs (a human factor). One producer shared how, unlike his father's generation, he comfortably and efficiently drives out "in a heated cab with a radio going, and feed[s] 350 head of cows, and it takes 20 minutes" (R25).

Participants emphasized that the human factor, i.e., attributes, knowledge, and physical abilities, required to ranch and farm have changed over the years. One producer stated, "Years ago when my poor father started ranching, why it was a lot of physical labor. Now it's much more management, administrative" (R29). When asked about the essential elements of being a rancher, interviewees emphasized the significance of personal attributes required for success, such as morals and resilience. One multi-generational producer stated:

I think [ranchers] need to be well-read. I think you need to be able to communicate well with the outside world and with the people around you. There's just a whole bunch of things I guess I'd have to say that are important. You need to be able to roll with the punches. You need to be able to handle adversity, handle disappointment, handle change. Handling change is a very key component of virtually any business, I think. Being able to take a situation that's foreign to you and keep moving on in spite of the problems. (R29)

In addition to evolving their operations to meet shifting social and ecological conditions, the above participant shared how producers themselves are adapting. For instance, in response to changes such as exurban growth and the growing public consciousness around food systems, some ranchers increasingly engage in the public sphere through entities such as producer organizations and collaborative management efforts. Moreover, as operations diversify in response to change, producers are driven to take on multiple roles that often require new knowledge and skills.

In terms of physical factors, participants discussed how technology has decreased labor demands, often increasing their subjective well-being. For some, technology, such as cameras, enabled them to "just roll over in bed and look at my phone" (R21) to check the calving barn. Yet, technological advances may not be accessible for all producers, and as one participant shared, "I could see a lot of, just technology being the future. If you don't embrace it, I'm afraid it'll run over you" (R21). Yet, interviewees also shared concerns about overspending on equipment that fails to generate returns for the operation.

\section{Political and cultural factors}

Although researchers and practitioners rarely integrate political and cultural factors into the SLA, this study supports Baumann's (2000) proposed inclusion of political factors. Participants identified access or "the ability to benefit from a thing" as central to political and cultural factors (Ribot and Peluso 2003:153). One participant outlined his use of political factors to inform resource governance:

\section{A dispute with the neighbor over surface water has forced us to form groundwater management districts, which are governed by the people within the district. The people that gave us the most support are the ones that are still giving us support, and they will be the directors of the groundwater management district. (R1)}

Above, social relationships changed, and as a result, the farmer's enforceable claims to water resources were contested. Ultimately, his ability to derive benefits from water resources depended on social relations, in this case via the negotiation of resource governance. This farmer's use of social relations to facilitate resource access supports participants' broader framing of social factors as foundational, aligning with the theory of access claim that power emerges from particular configurations of social relations (Ribot and Peluso 2003, Peluso and Ribot 2020).

In contrast, other participants expressed limited access to political factors, especially political power. Several participants felt that their rural identities limited their access to political influence, citing a lack of representation for rural people and places at the national, state, and in some cases, the county levels (Ribot and Peluso 2003). One participant articulated that national and statelevel politicians “don't understand the concept of rural America. Yeah, it doesn't really get heard. If you live in the flyover states, that's exactly what you are" (R18). Most participants expressed that they feel more meaningfully engaged in local-level politics. For example, one participant voiced contention with nationallevel policies but support for state and county-level staff of the national Farm Service Agency (FSA) because they "actually live" (R18) in the communities and can make changes. Several participants served on the local school board, the County Agriculture Council, numerous conservation initiatives, and several other local efforts. Although participants discussed the 
adverse effects of federal and global policies and institutions on their material well-being, they dedicated years of primarily unpaid work to local institutions to support the social and cultural aspects of life that contribute to their relational and subjective well-being.

For some participants, cultural factors, such as their family's history on the land, supported their commitment to agriculture. For example, while sharing her relationship to her family's pioneer history, one producer said, "You cannot live out here with the wind and not feel [that connection]" (R3). But, as a retired Larimer County producer shared, this way of life is changing for many:

Culture? I have seen a lot of change, like going from horses to tractors to all this modern equipment, you know. The elimination of labor, computers running, tractors running, the evolution of irrigation. You know? Farmers today do not irrigate like I did. I used to shovel. These people use a computer and a pad. You know? I was still of that generation. The culture, it's real. To me it is upsetting because the owners of the land are detached from it. The farmers that operate it just own equipment. (R4)

Above, the farmer reflected on how shifts in the practice of agriculture affect peoples' relationship to the land, capturing the linkage of natural and cultural factors (Flora and Thiboumery 2006, Pretty 2011). Such disconnection from the land can drive declines in cultural factors, cascading to affect identities, livelihoods, and well-being (Pretty 2011).

However, some participants viewed cultural shifts as an opportunity for advancement (Little et al. 2014). For instance, when asked if he experienced policy constraints, a first-generation Larimer rancher said, "I think social expectations probably have limited me and limited more people than politics do." $\mathrm{He}$ continued:

Well, I think we tell ourselves time and time again that you can't walk on the moon, right. You'll never be an astronaut. Well, as soon as you start telling yourself that - as soon as you let society tell you that's just impossible, that just doesn't happen - you start believing in it, and then it's done. It's gone. And I think that's more powerful than any law would ever be. (R10)

For the first-generation producer above, his lack of multigenerational history in agriculture allowed him to work "outside the margins" (R10). Below, one Larimer rancher shared his response to his community's changing demographics:

I try to understand people and then deal with it in a positive attitude. Because I mean, things aren't like the good ole days, are they? So, you just have to understand that. So, when the lady drives in here and says, "Your cow is dying." You just kind of look at them like this is a teaching moment. "Would you and your little girl like to go out there and watch her have her baby calf?” (R16)

Above, the participant shared his livelihood strategy that supports his cultural resilience in response to change (Crane 2010). He acknowledged his experience of cultural loss while also adaptively responding to change by educating community members about his way of life.
Well-being outcomes (material, subjective, and relational) Well-being consists of three interrelated dimensions: material, relational, and subjective. When producers discussed shorter term decisions in response to episodic challenges, such as drought, they focused their livelihood strategies on maintaining their material well-being. One couple described how the ability to maintain the material well-being of their business drives their decision to continue their operation, which in turn contributes to their identities as businesspeople:
[We are] mostly economically driven. I don't like that idea that we are farmers because that is what we want to be. We do it because we make money. We run it as a business. And of course, we like what we do, but we wouldn't do it if we didn't make money. (R1)

The connection between identity and the material outcomes, i.e., we are not farmers; we are business people, emphasizes the importance of material well-being to other facets of participants' livelihoods. For instance, although material well-being is easy to articulate and often a short-term priority, the material has implications for relational and subjective well-being.

Although producers frequently focused on material outcomes in response to near-term perturbations, e.g., extreme weather and economic downturns, they often oriented their longer term decisions around the relational dimension of well-being. Producers especially emphasized that family was the core of their complex social webs. From stories of parents driving through the night to help with calving season to a son unwilling to sell the farm because it is his mother's home, producers presented family as a driving force behind their long-term livelihood decisions. In addition to family, many producers expressed gratitude and a sense of well-being as they recounted community support during tornadoes, family losses, and illnesses. Still, in the context of rural change, older participants expressed losses to their relational wellbeing. For example, some struggled with the loss of "neighboring" culture or close community bonds. One retired participant shared, "In the old days, I think, that the farmers talked, and they associated with each other when I was growing up. But then in the 80 s, it was starting to break up" (R4). He believed that the challenges of the economic downturn created divides. Instead of fostering support through community social networks, people said, "I am not in that group, and I don't want to know about your problems" (R4). Moreover, when asked about change in his community, one Weld resident shared the following:

[Community change] upsets me. We had a bowling alley in [place name] [ that] they built in 1960 or so, and during my lifetime, I'd go [to] that bowling alley. In the back, they had a roller-skating rink. A lot of the people in the community bowled, and it was just a central community entertainment deal. This one guy bought it, and he didn't keep it up. People got mad, and they wouldn't come and stuff like that. So, I told him how I felt about it, and he said, "What the hell? It's mine. You don't need to tell me about how to run this business." Well, I do because this has been a source of my entertainment for lots of years, and you're screwing it up and it's pissing [me] off. Well, there's nothing in [place name] now. (R19)

This participant shared how the loss of rural public spaces can negatively affect well-being. 
As the last quotation captures, the subjective dimension of wellbeing is interrelated with the material and relational. Although participants often led with the importance of finances, the conversation frequently transitioned to reflective dialogue about people's relational and subjective well-being. For example, as we stood outside during a cold fall night next to a producer's favorite animal, she shared, "We live out here because we want our skies" (R13). Here, the producer captured how a connection to the place and the environment (natural factor) contribute to some people's subjective well-being. She shared how nature's role in her relational and subjective well-being drives her and her husband's major life decisions, including their occupations.

Alternatively, another producer shared how the challenges of livestock production can negatively affect subjective well-being:

\section{We always talk about management and things like that. But, how do you deal with the stressors of what you do? Because we look at the business side of it, and in normal industries, you get to leave. When I bail out of bed, I'm at work. When I go to bed, I'm still at work. How do you deal with constantly being bombarded? (R11)}

The producer positioned ranching outside of "normal industries," suggesting a need for tailored support for people engaged in farm and ranch work. Some producers expressed interest in education and programs around communication skills, fostering a sense of community, and mental health. The above producer identified a need for facilitated peer-to-peer discussions about ranching's personal and management struggles, cultivating space for dialogue and connection among people with shared experiences.

Although participants shared the challenges of ranching, they also conveyed their appreciation for their way of life. One producer said, "I go out there and ride through [the fields] with the four-wheeler every day. I enjoy that. I really enjoy that, talking to the cows." He goes on to say, "Well, I'm already living the dream. Yeah, with a little bit of oil and stuff. I took a picture for my mom, and it's a picture of ... 10 oil tanks and an oil well, and there's cows on green grass" (R17). This producer's subjective well-being and access to oil income help mitigate some of his challenges, such as political disempowerment. Still, he shared that these challenges were manageable given his close relationships with other community members (i.e., relational), financial security (i.e., material), and appreciation for his way of life (i.e., subjective well-being). A different Weld County producer reflected on how his money went to his family, which created a life worth living:

\begin{abstract}
When we had \$1700, Isaid, "That's a wonderfulnumber." [My wife] said, "What's so wonderful about that?" I said, "Well, geez, look at it like this." I said, "When you and I got married in 1971, we had $\$ 1700$. We raised two kids, our house is paid for, and we still got the $\$ 1700$. We sent them to college; we still got the $\$ 1700$. What more could you ask for?" (R19)
\end{abstract}

Above, the participant shared how his balance across the triad of material, relational, and subjective outcomes created a resilient state of well-being.

\section{Social and ecological change in northeastern Colorado}

When asked to discuss their histories as livestock producers, participants recurrently shared the significance of change. Yet, participants often expressed different sentiments regarding change. For instance, one Weld County producer explained the progressive abandonment of eastern Plains communities:

There are other towns that I knew about when I was a kid. A town called [place name] that is completely gone - you just find foundations there. And you go on down the road, there's a little town called [place name], and it's got some empty buildings there, but nobody lives there. And you go on to Highway 14, and you come to a little town called [place name], and it's gone. (R19)

One retired Larimer farmer predicted a system transformation:
I think in this area agriculture will die. As Florida gets deeper and deeper into the water, they are going to move up here to stay dry, and we are going to farm Iowa and Nebraska and places where there is more productive land than this. We are going to put houses here. (R4)

Although the above farmers shared past and projected future losses due to change, one multi-generation rancher reflected that technology changes have positively facilitated "the coming together of the rural and urban societies" (R29). He continued to explain how these changes, specifically those that have increased communication and mobility, have positively affected the ranching community's subjective well-being and agricultural productivity:
I think agriculture in general, because of [advancements in technology], is more able to take advantage of opportunities, is better managed than it ever used to be. I guess that's the best way I can put it. I just think that people are happier out there, and they perform better, and the ranches are more successful. That they exist has been a great consolidation of our issues. But, in general, the whole ranching business is much more able to survive when they know what the rest of the world is doing. (R29)

The above rancher emphasized the connection of ranching to larger economic systems that drive change at the local level. Given the context of change, a common question remained: How do producers use their resources to develop adaptive strategies to shape desired livelihood and well-being outcomes? For example, after learning about predicted shifts in native plant communities in response to increased carbon dioxide levels, one Weld producer inquired, "How will I adapt to the new plant community?" (R7). Similarly, a Larimer producer asked, "As urban sprawl occurs, is society going to be welcoming to traditional agriculture? Are they going to be expecting agriculture to look different?" (R10).

\section{Adaptive livelihoods and well-being strategies}

Below, we use our integrated livelihoods and well-being framework to illustrate four cases of producer decision making in response to social or ecological change. The first case depicts a spiral of decline. In contrast, each of the other three cases illustrates a distinct strategy used to maintain or increase wellbeing during shocks like drought or economic downturns. 


\section{Spiral of decline}

Livestock producers identified shocks and stresses such as extreme weather, family health crises, urbanization, and severe economic downturns as events that drive a spiral of decline, as the Weld producer in Figure 4 narrates. Some livelihoods research frames such exoduses from agriculture as a livelihood strategy of migration (e.g., Scoones 1998). We observed migration out of agriculture not as a strategy but as a forced transition in which producers have restricted agency.

Fig. 4. The integrated sustainable livelihoods approach and well-being framework for northeastern Colorado livestock producers capturing a multi-factor cycle of decline, with orange depicting losses. (1) First, the operation was hit with drought, further challenging the financial factor. (2) The financial and natural losses influenced a loss of pride or subjective wellbeing. (3) This loss of financial, natural, and subjective wellbeing affected a decline of material well-being. (4) Last, these losses sparked the system transforming cycle of decline and migration out of agriculture.

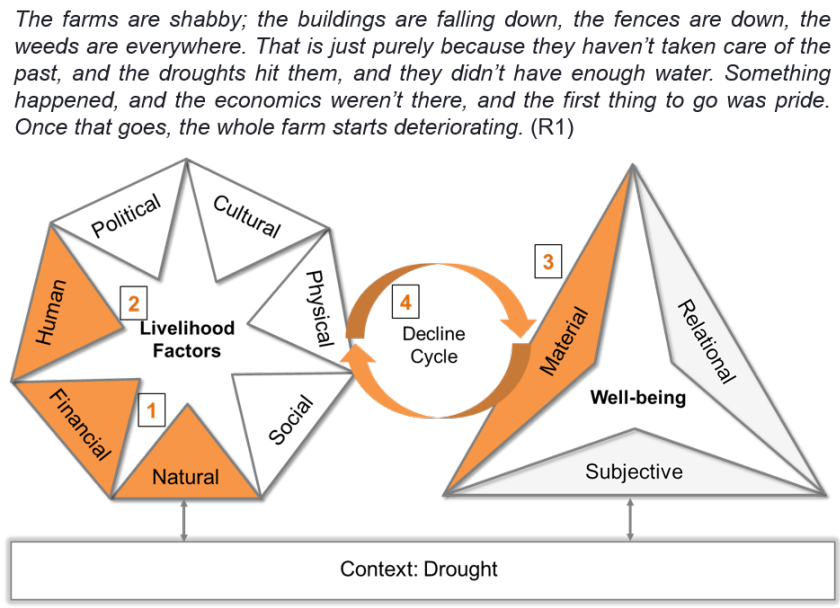

Avoiding the spiral of decline through contraction, expansion, or diversification

Although livelihood strategies are complicated and specific to the operation's context, we identified three broad livelihood strategies that producers used to avoid spirals of decline when challenged: contraction, expansion, and diversification. For one small-scale Larimer rancher, limited resources require contraction in response to challenges:

I try to figure out what is the minimum that I can deal with ... I have sold a lot of lambs this year that I might have kept otherwise, and I probably have another load, probably 10 to 20 more, that needs to go. I have sold all of the older ones and such. And now it is time to start thinking about selling lambs, which is sad because they are going to take you forward. (R3)

Others shared this rancher's contraction strategy, some drawing heavily on one resource to preserve another, such as temporarily overgrazing to reduce cattle sales. In more extreme situations, producers sold parts of their operations. Moreover, a Weld producer explained a long-term strategy of selling commercial cattle to preserve grazing land and registered animals (Fig. 5). As the drought progressed and destocking cows from the commercial cow-calf pairs were insufficient, the producer used his physical infrastructure to maintain calves in the feedlot. These combined strategies preserved his high-value resources, enabling the producer to rebound from the drought effectively.

Fig. 5. The integrated sustainable livelihoods approach and well-being framework for northeastern Colorado livestock producers illustrating a contraction strategy, with orange depicting losses and blue indicating elements that gained or maintained. (1) First, severe drought negatively impacted the natural factor. (2) To maintain the high-value natural factor, the producer leveraged his financial factor in the form of commercial cattle to reduce grazing. (3) As the drought progressed and the commercial animals' reduction was insufficient, the producer utilized the physical infrastructure to maintain calves in the feedlot. (4) These combined strategies preserved the high-value resources of grazing land and registered cattle, enabling the producer to rebound from the drought effectively.

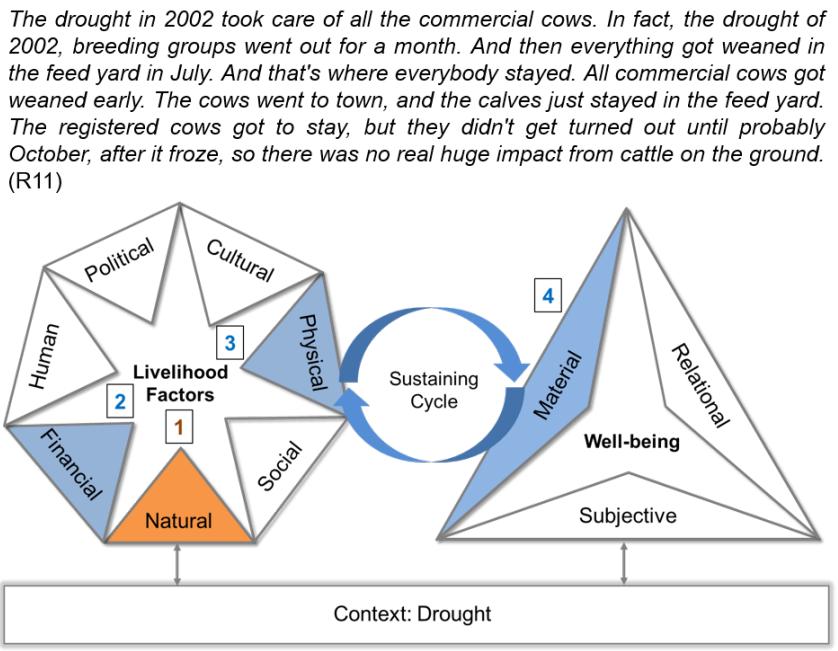

In contrast to the cases above, the couple below found opportunity for expansion in economic downturns:

And in [a cow's] 12-year lifespan, her value is going to go up and down, up and down. Well, most ranchers never take advantage of the up or the down ... In a 12-month period, cow prices are up, we're selling cows, we're selling our most overpriced cows that we own, and then we're replacing them with lower value ... So, we're taking advantage of [market changes], and what we like to see in the cattle market is movement. We like the market to go up, and we really like the market to go down because we've learned how to generate a tremendous amount of cash flow from the top and the bottom and maintain our inventory ... We've learned to manage this total dollar amount of our inventory so if [cattle prices] get too high, we sell back to this base level. When it drops way below that base level, we have that money to buy more head. (R28)

These ranchers leveraged their human factor in the form of knowledge, finances, and social network to purchase cattle in a market downturn. They move their cattle inventory quickly to 
capture profit through market gains. Similarly, some producers, such as the one in Figure 6, purchase more land during market lows. This producer's expansion strategy likely contributed to his role as a community leader and growth to $12,000+$ acres and $50,000+$ head of cattle.

Fig. 6. The integrated sustainable livelihoods approach and well-being framework for northeastern Colorado livestock producers illustrating a strategy of expansion when challenged, with orange depicting losses and blue indicating elements that gained or maintained. (1) First, the economic downturn in the 1980s left the producer unable to sell out. (2) In response to financial challenges and limited access to other livelihood strategies, the producer invested in acreage when the market was low. (3) Because of their ability to increase property despite challenges with financial institutions, the producer maintained their industry through the 1980 s downturn, and today, they are a largescale operator.

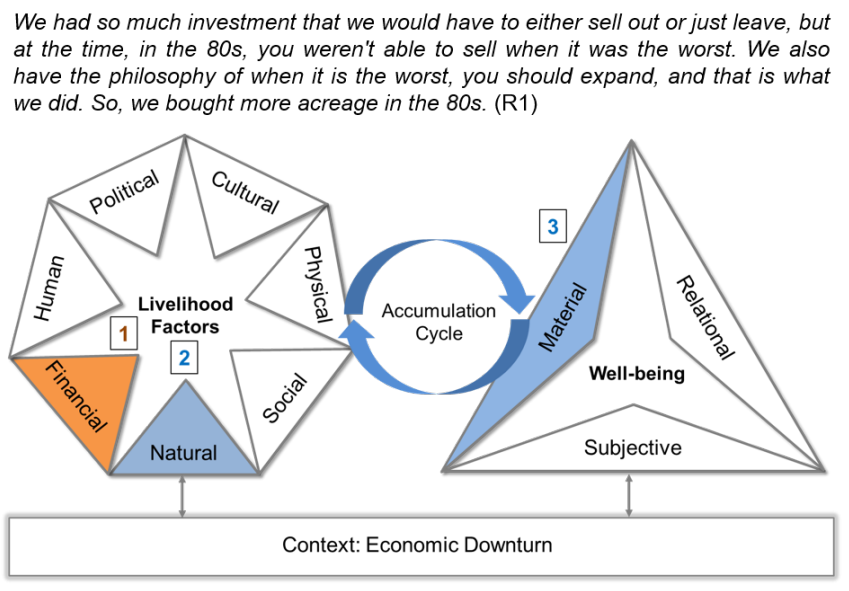

We identified diversification as a critical strategy to smooth income, optimize equipment, and mitigate risk. Producers discussed diversification as both an adaptive and coping response, like one Weld producer's use of multiple diversification strategies in extreme drought (Fig. 7). The producer's decision to diversify across sectors and vertically integrate within the cattle industry, such as investing further into a feedlot, sustained his operation through the drought. Livestock owners shared how they leveraged their existing wells of livelihood factors to assemble these adaptive strategies - contraction, expansion, and diversification-to maintain or enhance their well-being and livelihood factors in the face of rapid social and ecological change.

\section{DISCUSSION AND IMPLICATIONS}

Grounded in our analysis of NE Colorado livestock producers' lived experiences, we proposed and applied an integrated SLA and well-being framework that sheds light on the interplay between ranchers' livelihood decisions and well-being (Delmar 2010). Below, we discuss this framework's contribution to socialecological-emotional systems' conceptualization and advocate for continued theorization. We also offer that the integrated framework can support the incorporation of human well-being and sustainable livelihoods into producer outreach programs. As such, this study offers further research directions in rancher decision making and, more broadly, in sustainable livelihoods and well-being.

Fig. 7. The integrated sustainable livelihoods approach and well-being framework for northeastern Colorado livestock producers illustrating a strategy of diversification, with orange depicting losses and blue indicating elements that gained or maintained. (1) First, drought hit the operation, and as a result, the natural factor was reduced, eliminating crops and reducing grazing. (2) Given the loss of natural resources, the producer used his physical factor of a feedlot and his social network to custom feed local producers' cattle. (3) Despite the loss of grazing resources and crops, the producer's vertical integration strategy in the cattle industry enabled the maintenance of material well-being.

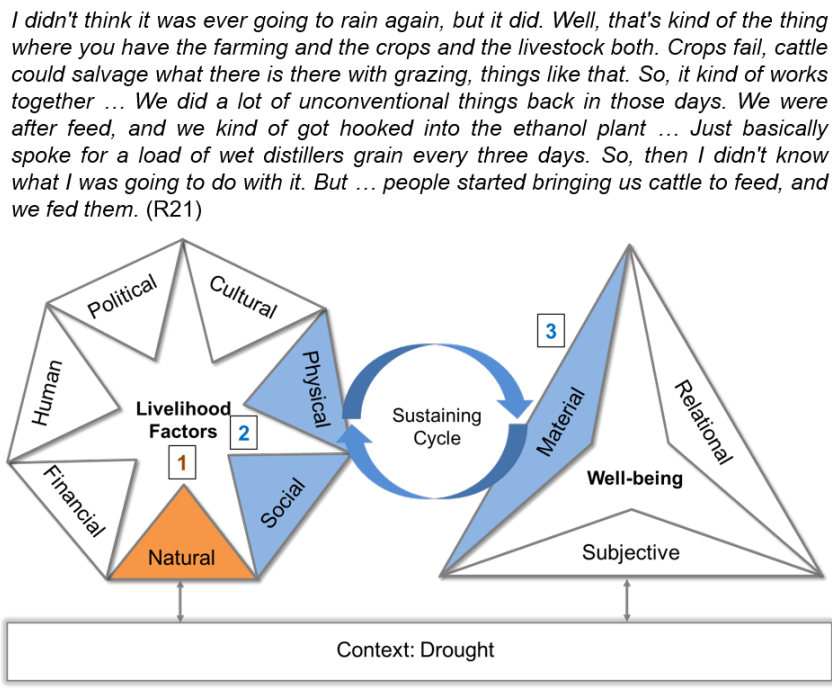

\section{Theoretical advancements}

We propose that scholars and practitioners apply this integrated framework to conceptualize social-ecological-emotional livestock systems in Colorado and the U.S. more broadly. The significance of subjective well-being, i.e., the emotional sphere, to livelihood strategies emerged from this empirical qualitative study, addressing the need to examine subjective lived experiences in SESs research (Coulthard 2012, Stojanovic et al. 2016, Schlüter et al. 2019, Elsawah et al. 2020). Moreover, this work addresses a lack of livelihoods research in the Global North rangelands, contextualizing a holistic livelihoods approach of "a living" to producer decision making in NE Colorado. This framework is an early contribution to theory, which we expect will continue to evolve through the dynamic and adaptive process of theory building. For instance, applications to other sites and systems will expand this study's insights beyond Colorado to widely support the development of socially, ecologically, and emotionally sustainable livestock systems (Firestone 1993). Moreover, this contextualized framework offers insights to the broader livelihood and well-being frameworks (Hong et al. 2014). Future research could examine if the proposed integration of livelihoods and well-being extends to a diversity of SESs, such as other rangeland/pastoral settings, fisheries, forest-based or farming systems, to name a few. 
Our proposed framework captures the social, ecological, and emotional dimensions of change. For instance, the framework enriches our understanding of the effects of well-being, such as feelings of pride, on livelihood factors and, in turn, adaptive strategies. As such, well-being is not framed as a static outcome but as one of the many critical elements in complex adaptive systems. Well-being is also highly personal, and therefore, our integrated framework leverages the capacity of the well-being approach to capture some of the heterogeneity among ranchers and farmers (Deneulin and McGregor 2010). The proposed framework does not assume that all people in a system have the same goal, e.g., financial gains. For instance, although some producers' might feel a sense of subjective well-being from a connection to their heritage, others within the same system may not garner well-being from cultural factors. Instead, the integration of well-being supports researchers in understanding peoples' differing goals and associated strategies. For example, aligned with the place-attachment literature (Lewicka 2011), our findings indicate that some peoples' goal is to maintain their subjective well-being by continuing to live at home, whether defined by the dwelling, land, or community. Thus, these individuals are willing to adapt their livelihood strategies to achieve this goal. We posit that this framework may guide researchers in identifying such previously unconsidered influences of human well-being on adaptive strategies.

Moreover, this research adds qualitative depth to the predominately quantitative literature on rancher decision making (Bruno et al. 2020). In this analysis, both political and cultural factors emerged in our integrated livelihoods and well-being framework, reflecting a central critique that SES scholarship depoliticizes the social (Smith and Stirling 2010, Glaser and Glaeser 2011, MacKinnon and Derickson 2012, Fabinyi et al. 2014, Welsh 2014). Specific to rangelands in the western U.S., research has identified ranchers as having high degrees of political factors and cultural significance (e.g., Donahue 1999). Yet, this research found that some ranchers and farmers lacked access to political and cultural factors. Aligned with Ribot and Peluso's (2003) theory of access, we found that natural and social factors mediated access to political factors. This finding raises questions about who has access to political and cultural factors on western rangelands. We posit that rangeland social science's limited consideration of diverse stakeholders on North American rangelands has left issues of access disparity of political and cultural factors underexamined (Bruno et al. 2020). In the future, researchers could apply this framework to examine disparities in access to political and cultural factors in North American rangelands.

\section{Extension and outreach implications}

In practice, similar to the recommendations of Woodhouse et al. (2015) and Biedenweg et al. (2017), our findings highlight the importance of social well-being support in natural resources outreach, such as in drought response planning and programs. Furthermore, our systems framing leads us to speculate that continued failure to address human well-being in most natural resources and agriculture programming could negatively influence livestock keepers' adaptive capacity. Therefore, we emphasize continued support for outreach and extension initiatives focused on producer well-being, such as the University of Maine's Farm Coaching program (https://extension.umaine. edu/beginning-farmer-resource-network/farm-coaching-supportingrelationships-for-farm-success/), Montana State University's Montana Ag Producer Stress Resource Clearinghouse (https:// msuextension.org/wellness/stress-management/mt farm_stress clearing house/), and Holistic Management programming, e.g., Holistic Management International (Savory and Butterfield 2016). Further, natural resources programs could consider the expanded use of peer networks, such as those created in the Women, Food and Agriculture Network (Wells 1998), to support producers' relational and subjective well-being.

Our findings also offer insight into livestock keepers' adaptive livelihood strategies: diversification, contraction, and expansion. We found that diversification was the most widespread livelihood strategy employed by ranchers in the face of challenges, highlighting the opportunity for extension and outreach programs that support off- and on-operation diversification. Its pervasiveness in both our data and the broader literature (Barbieri et al. 2008, Barbieri and Mahoney 2009, Gutwein and Goldstein 2013) indicates producer eagerness to explore diversification. Barbieri and Mahoney (2009) demonstrate how diversification is an effective farm or ranch restructuring strategy in response to change. Similarly, Lin (2011) found that crop diversification that increases structural, i.e., agroforestry, and ecological, i.e., incorporation of wild varieties, complexity can increase farmers' resilience to climate change. Despite its potential as an adaptive strategy, barriers - policies, markets, uncertain land tenure, and the land's limited capacity to support differing land uses - may hinder diversification (Brandth and Haugen 2011, Herrick et al. 2012, Sayre et al. 2012, Maaz et al. 2018). Given that management "panaceas" are non-existent (Ostrom 2007), we advocate for "toolbox" approaches to diversification, i.e., a set of opportunities that producers can select and adapt to their context and needs.

In contrast to diversification, producers held divergent views of expansion and contraction as livelihood strategies. Although some producers found opportunities during challenges, others were forced to reduce their assets or operations, often to preserve their highest value resources. As some producers are forced to sell land or animals, others purchase these resources, consolidating holdings into a few large-scale, often corporate-owned operations. We speculate that the co-occurrence of contraction and expansion strategies in shared geographies may facilitate the loss of familyowned operations. Further research might consider how access to livelihood factors influences producers' decisions to expand or contract. Additionally, a land-use change analysis could explore how both expansion and contraction strategies during socioeconomic or ecological downturns affect a region (e.g., Knapp 2008).

\section{CONCLUSIONS}

We present an empirical foundation for an integrated livelihood and well-being framework grounded in NE Colorado livestock producers' experiences. The framework theorizes reciprocal relationships between livelihood decisions and human well-being outcomes. We also applied our framework to illustrate a spiral of livelihood and well-being decline and three adaptive strategies that improved well-being: contraction, expansion, and diversification. We advocate for applying this framework to other sites and systems, expanding these research insights on the 
interplay between livelihoods and well-being beyond northeastern Colorado to widely support the development of socially, ecologically, and emotionally sustainable livestock systems.

This study also emphasizes the significance of well-being and resource access to producers' livelihood decision making. As such, we suggest that outreach and research involving livestock producers are likely to achieve greater success when programming addresses human well-being and resource access inequities. Last, our findings highlight the importance of diversification to ranch adaptation. Therefore, we recommend continued extension and outreach programming that supports farmers' and ranchers' onand off-operation diversification strategies.

Responses to this article can be read online at: https://www.ecologyandsociety.org/issues/responses. php/12754

\begin{abstract}
Acknowledgments:
We thank the participants who graciously invited us into their homes and shared their best and worst days of livestock production. A special thanks to members of the Human Dimensions Lab at Colorado State University, especially Cara Steger, for your review of early versions of this manuscript and to two anonymous reviewers. The Colorado Agricultural Experiment Station COL00769 provided funding for this research.
\end{abstract}

\section{Data Availability:}

The data that support the findings of this study are available on request from the corresponding author, $J B$. The data are not publicly available because of their containing information that could compromise the privacy of research participants.

\section{LITERATURE CITED}

Agarwala, M., G. Atkinson, B. Palmer Fry, K. Homewood, S. Mourato, J. Marcus Rowcliffe, G. Wallace, and E. MilnerGulland. 2014. Assessing the relationship between human wellbeing and ecosystem services: a review of frameworks. Conservation and Society 12(4):437-449. https://doi.

org/10.4103/0972-4923.155592

Armitage, D., C. Béné, A. T. Charles, D. Johnson, and E. H. Allison. 2012. The interplay of well-being and resilience in applying a social-ecological perspective. Ecology and Society 17 (4):15. https://doi.org/10.5751/ES-04940-170415

Barbieri, C., and E. Mahoney. 2009. Why is diversification an attractive farm adjustment strategy? Insights from Texas farmers and ranchers. Journal of Rural Studies 25(1):58-66. https://doi. org/10.1016/j.jrurstud.2008.06.001

Barbieri, C., E. Mahoney, and L. Butler. 2008. Understanding the nature and extent of farm and ranch diversification in North America. Rural Sociology 73(2):205-229. https://doi. org/10.1526/003601108784514543
Baumann, P. 2000. Sustainable livelihoods and political capital: arguments and evidence from decentralisation and natural resource management in India. Overseas Development Institute, London, UK.

Beauchamp, E., E. Woodhouse, T. Clements, and E. J. MilnerGulland. 2018. "Living a good life": conceptualizations of wellbeing in a conservation context in Cambodia. Ecology and Society 23(2):28. https://doi.org/10.5751/es-10049-230228

Biedenweg, K., H. Harguth, and K. Stiles. 2017. The science and politics of human well-being: a case study in cocreating indicators for Puget Sound restoration. Ecology and Society 22(3):11. https://doi.org/10.5751/es-09424-220311

Binder, C. R., J. Hinkel, P. W. G. Bots, and C. Pahl-Wostl. 2013. Comparison of frameworks for analyzing social-ecological systems. Ecology and Society 18(4):26. https://doi.org/10.5751/ ES-05551-180426

Brandth, B., and M. S. Haugen. 2011. Farm diversification into tourism-implications for social identity? Journal of Rural Studies 27(1):35-44. https://doi.org/10.1016/j.jrurstud.2010.09.002

Breckenridge, J., and D. Jones. 2009. Demystifying theoretical sampling in grounded theory research. Grounded Theory Review 8(2):113-126.

Briske, D. D., L. A. Joyce, H. W. Polley, J. R. Brown, K. Wolter, J. A. Morgan, B. A. McCarl, and D. W. Bailey. 2015. Climatechange adaptation on rangelands: linking regional exposure with diverse adaptive capacity. Frontiers in Ecology and the Environment 13(5):249-256. https://doi.org/10.1890/140266

Brown, J. R., and J. Thorpe. 2008. Climate change and rangelands: responding rationally to uncertainty. Rangelands 30(3):3-6. https://doi.org/10.2111/1551-501x(2008)30[3:ccarrr]2.0.co;2

Bruno, J. E., C. Jamsranjav, K. E. Jablonski, E. G. Dosamantes, H. Wilmer, and M. E. Fernández-Giménez. 2020. The landscape of North American rangeland social science: a systematic map. Rangeland Ecology and Management 73(1):181-193. https://doi. org/10.1016/j.rama.2019.10.005

Brunson, M. W. 2012. The elusive promise of social-ecological approaches to rangeland management. Rangeland Ecology \& Management 65(6):632-637. https://doi.org/10.2111/REM-D-11-00117.1

Burton, R. J. F. 2004. Reconceptualising the 'behavioural approach' in agricultural studies: a socio-psychological perspective. Journal of Rural Studies 20(3):359-371. https://doi. org/10.1016/j.jrurstud.2003.12.001

Cash, D. W., W. N. Adger, F. Berkes, P. Garden, L. Lebel, P. Olsson, L. Pritchard, and O. Young. 2006. Scale and cross-scale dynamics: governance and information in a multilevel world. Ecology and Society 11(2):8. https://doi.org/10.5751/ES-01759-110208

Chambers, R. 1992. Sustainable livelihoods: the poor's reconciliation of environment and development. Pages 214-229 in P. Ekins and M. Max-Neef, editors. Real-life economics: understanding wealth creation. Routledge, London, UK.

Chambers, R. 1995. Poverty and livelihoods: whose reality counts? Environment and Urbanization 7(1):173-204. https:// doi.org/10.1177/095624789500700106 
Chambers, R., and G. R. Conway. 1992. Sustainable rural livelihoods: practical concepts for the 21 st century. IDS Discussion Paper. Institute of Development Studies, Brighton, UK.

Charmaz, K. 2006. Constructing grounded theory: a practical guide through qualitative analysis. SAGE, Thousand Oaks, California, USA.

Charmaz, K. 2008. Grounded theory as an emergent method. Pages 155-172 in S. N. Hesse-Biber and P. Leavy, editors. Handbook of emergent methods. Guilford, New York, New York, USA.

Coles, A. R., and C. A. Scott. 2009. Vulnerability and adaptation to climate change and variability in semi-arid rural southeastern Arizona, USA. Natural Resources Forum 33(4):297-309. https:// doi.org/10.1111/j.1477-8947.2009.01253.x

Coulthard, S. 2012. Can we be both resilient and well, and what choices do people have? Incorporating agency into the resilience debate from a fisheries perspective. Ecology and Society 17(1):4. https://doi.org/10.5751/ES-04483-170104

Coyne, I. T. 1997. Sampling in qualitative research. Purposeful and theoretical sampling; merging or clear boundaries? Journal of Advanced Nursing 26(3):623-630. https://doi.org/10.1046/ j.1365-2648.1997.t01-25-00999.x

Crane, T. A. 2010. Of models and meanings: cultural resilience in social-ecological systems. Ecology and Society 15(4):19. https:// doi.org/10.5751/ES-03683-150419

Davis, C. 2012. The politics of "fracking": regulating natural gas drilling practices in Colorado and Texas. Review of Policy Research 29(2):177-191. https://doi.org/10.1111/j.1541-1338.2011.00547. $\underline{x}$

Dawson, N., and A. Martin. 2015. Assessing the contribution of ecosystem services to human wellbeing: a disaggregated study in western Rwanda. Ecological Economics 117:62-72. https://doi. org/10.1016/j.ecolecon.2015.06.018

Delmar, C. 2010. "Generalizability” as recognition: reflections on a foundational problem in qualitative research. Qualitative Studies 1(2):115-128. https://doi.org/10.7146/qs.v1i2.3828

Deneulin, S., and J. A. McGregor. 2010. The capability approach and the politics of a social conception of wellbeing. European Journal of Social Theory 13(4):501-519. https://doi. org/10.1177/1368431010382762

Donahue, D. 1999. The western range revisited: removing livestock from public lands to conserve native biodiversity. The University of Oklahoma Press, Norman, Oklahoma, USA.

Elsawah, S., T. Filatova, A. J. Jakeman, A. J. Kettner, M. L. Zellner, I. N. Athanasiadis, S. H. Hamilton, R. L. Axtell, D. G. Brown, J. M. Gilligan, M. A. Janssen, D. T. Robinson, J. Rozenberg, I. I. T. Ullah, and S. J. Lade. 2020. Eight grand challenges in socio-environmental systems modeling. SocioEnvironmental Systems Modelling 2:16226. https://doi. org/10.18174/sesmo.2020a16226

Emery, M., and C. Flora. 2006. Spiraling-up: mapping community transformation with community capitals framework.
Community Development 37(1):19-35. https://doi. org/10.1080/15575330609490152

Escalera-Reyes, J. 2020. Place attachment, feeling of belonging and collective identity in socio-ecological systems: study case of Pegalajar (Andalusia-Spain). Sustainability 12(8):3388. https:// doi.org/10.3390/su12083388

ESRI. 2011. ArcGIS desktop release 10. Environmental Systems Research Institute, Redlands, California, USA.

Fabinyi, M., L. Evans, and S. J. Foale. 2014. Social-ecological systems, social diversity, and power: insights from anthropology and political ecology. Ecology and Society 19(4):28. https://doi. org/10.5751/ES-07029-190428

Firestone, W. A. 1993. Alternative arguments for generalizing from data as applied to qualitative research. Educational Researcher 22(4):16-23. https://doi.org/10.3102/0013189X022004016

Flora, C., M. Emery, S. Fey, and C. Bregendahl. 2004. Community capitals: a tool for evaluating strategic interventions and projects. North Central Regional Center for Rural Development, Ames, Iowa, USA.

Flora, C. B., and A. Thiboumery. 2006. Community capitals: poverty reduction and rural development in dry areas. Annals of Arid Zone 45(3-4):239-253.

Fry, B. P., M. Agarwala, G. Atkinson, T. Clements, K. Homewood, S. Mourato, J. M. Rowcliffe, G. Wallace, and E. J. Milner-gulland. 2017. Monitoring local well-being in environmental interventions: a consideration of practical tradeoffs. Oryx 51(1):68-76. https://doi.org/10.1017/s003060531500112x

Glaser, M., and B. Glaeser. 2011. The social dimension of socialecological management. Pages 5-30 in E. Wolanski and D. S. McLusky, editors. Treatise on estuarine and coastal science. Academic, Waltham, Massachusetts, USA. https://doi. org/10.1016/B978-0-12-374711-2.01103-7

Goffman, E. 1989. On fieldwork. Journal of Contemporary Ethnography 18(2):123. https://doi.org/10.1177/089124189018002001

Grossman, L. 1977. Man-environment relationships in anthropology and geography. Annals of the Association of American Geographers 67(1):126-144. https://doi.org/10.1111/ j.1467-8306.1977.tb01124.x

Guetterman, T. C., W. A. Babchuk, M. C. Howell Smith, and J. Stevens. 2019. Contemporary approaches to mixed methodsgrounded theory research: a field-based analysis. Journal of Mixed Methods Research 13(2):179-195. https://doi. org/10.1177/1558689817710877

Gutwein, M., and J. H. Goldstein. 2013. Integrating conservation and financial objectives on private rangelands in northern Colorado: rancher and practitioner perceptions. Rangeland Ecology and Management 66(3):330-338. https://doi.org/10.2111/ REM-D-11-00206.1

Herrick, J. E., J. R. Brown, B. T. Bestelmeyer, S. S. Andrews, G. Baldi, J. Davies, M. Duniway, K. M. Havstad, J. W. Karl, D. L. Karlen, D. P. C. Peters, J. N. Quinton, C. Riginos, P. L. Shaver, D. Steinaker, and S. Twomlow. 2012. Revolutionary land use 
change in the 21st century: is (rangeland) science relevant? Rangeland Ecology \& Management 65(6):590-598. https://doi. org/10.2111/REM-D-11-00186.1

Holling, C. S. 1973. Resilience and stability of ecological systems. Annual Review of Ecology and Systematics 4(1):1-23. https://doi. org/10.1146/annurev.es.04.110173.000245

Hong, W., F. K. Y. Chan, J. Y. L. Thong, L. C. Chasalow, and G. Dhillon. 2014. A framework and guidelines for context-specific theorizing in information systems research. Information Systems Research 25(1):111-136. https://doi.org/10.1287/isre.2013.0501

Hruska, T., L. Huntsinger, M. Brunson, W. Li, N. Marshall, J. L. Oviedo, and H. Whitcomb. 2017. Rangelands as social-ecological systems. Pages 263-302 in D. D. Briske, editor. Rangeland systems: processes, management and challenges. Springer, Cham, Switzerland. https://doi.org/10.1007/978-3-319-46709-2 8

Huang, R. 2014. RQDA: R-based qualitative data analysis.

Huntsinger, L., and J. L. Oviedo. 2014. Ecosystem services are social-ecological services in a traditional pastoral system: the case of California's Mediterranean rangelands. Ecology and Society 19(1):8. https://doi.org/10.5751/ES-06143-190108

Hussein, K. 2002. Livelihoods approaches compared: a multiagency review of current practice. Department for International Development, London, UK. [online] URL: https://www. researchgate.net/profile/Karim-Hussein-4/publication/278405226_Livelihoods_Approaches_Compared_A_Multi-

Agency Review of Current Practice/links/593946f1458515320607be7a/ Livelihoods-Approaches-Compared-A-Multi-Agency-Review-ofCurrent-Practice.pdf

Jacobs, S., N. Dendoncker, B. Martín-López, D. N. Barton, E. Gomez-Baggethun, F. Boeraeve, F. L. McGrath, K. Vierikko, D. Geneletti, K. J. Sevecke, N. Pipart, E. Primmer, P. Mederly, S. Schmidt, A. Aragão, H. Baral, R. H. Bark, T. Briceno, D. Brogna, P. Cabral, R. De Vreese, C. Liquete, H. Mueller, K. S. H. Peh, A. Phelan, A. R. Rincón, S. H. Rogers, F. Turkelboom, W. Van Reeth, B. T. van Zanten, H. K. Wam, and C. L. Washbourn. 2016. A new valuation school: integrating diverse values of nature in resource and land use decisions. Ecosystem Services 22:213-220. https:// doi.org/10.1016/j.ecoser.2016.11.007

Judkins, G., M. Smith, and E. Keys. 2008. Determinism within human-environment research and the rediscovery of environmental causation. Geographical Journal 174(1):17-29. https://doi.org/10.1111/j.1475-4959.2008.00265.x

Knapp, C. N. 2008. Knowledge with a place: exploring rancher knowledge of history and ecology in the Elkhead watershed in northwest Colorado. Thesis. Colorado State University, Fort Collins, Colorado, USA.

Kydd, J., A. Dorward, J. Morrison, and G. Cadisch. 2004. Agricultural development and pro-poor economic growth in subSaharan Africa: potential and policy. Oxford Development Studies 32(1):37-57. https://doi.org/10.1080/1360081042000184110

Lauenroth, W. K., I. C. Burke, and J. A. Morgan. 2008. The shortgrass steppe: the region and research sites. Pages 3-8 in W. K. Lauenroth and I. C. Burke, editors. Ecology of the shortgrass steppe: a long-term perspective. Oxford University Press, New
York, New York, USA. https://doi.org/10.1093/oso/9780195135$\underline{824.003 .0005}$

Lewicka, M. 2011. Place attachment: how far have we come in the last 40 years? Journal of Environmental Psychology 31 (3):207-230. https://doi.org/10.1016/j.jenvp.2010.10.001

Lin, B. B. 2011. Resilience in agriculture through crop diversification: adaptive management for environmental change. BioScience 61(3):183-193. https://doi.org/10.1525/bio.2011.61.3.4

Lincoln, Y. S., and E. G. Guba. 1986. But is it rigorous? Trustworthiness and authenticity in naturalistic evaluation. New Directions for Program Evaluation 30:73-84. https://doi. org/10.1002/ev. 1427

Little, W., S. Vyain, G. Scaramuzzo, S. Cody-Rydzewski, H. Griffiths, E. Strayer, and N. Keirns. 2014. Culture. Pages 78-112 Introduction to sociology-1st Canadian edition. BC Campus, Victoria, British Columbia, Canada.

Liu, J., T. Dietz, S. R. Carpenter, C. Folke, M. Alberti, C. L. Redman, S. H. Schneider, E. Ostrom, A. N. Pell, J. Lubchenco, W. W. Taylor, Z. Ouyang, P. Deadman, T. Kratz, and W. Provencher. 2007. Coupled human and natural systems. Ambio 36(8):639-649. https://doi.org/10.1579/0044-7447(2007)36[639: CHANS]2.0.CO;2

Maaz, T., J. D. Wulfhorst, V. McCracken, J. Kirkegaard, D. R. Huggins, I. Roth, H. Kaur, and W. Pan. 2018. Economic, policy, and social trends and challenges of introducing oilseed and pulse crops into dryland wheat cropping systems. Agriculture, Ecosystems and Environment 253(1):177-194. https://doi. org/10.1016/j.agee.2017.03.018

MacKinnon, D., and K. D. Derickson. 2012. From resilience to resourcefulness: a critique of resilience policy and activism. Progress in Human Geography 37(2):253-270. https://doi. org/10.1177/0309132512454775

McGregor, A., and A. Sumner. 2010. Beyond business as usual: what might 3-D wellbeing contribute to MDG momentum? IDS Bulletin 41(1):104-112. https://doi.org/10.1111/j.1759-5436.2010.00111. $\underline{\mathrm{X}}$

McGregor, J. A. 2008. Wellbeing, poverty and conflict. WeD Policy Briefing 01/08. Wellbeing in Developing Countries ESRC Research Group, Bath, UK. [online] URL: http://www.bath.ac. uk/soc-pol/welldev/research/bp/bp1-08.pdf

Meadows, D. 2008. Thinking in systems: a primer. Chelsea Green, White River Junction, Vermont, USA.

Milchunas, D. G., W. K. Lauenroth, and I. C. Burke. 1998. Livestock grazing: animal and plant biodiversity of shortgrass steppe and the relationship to ecosystem function. Oikos 83 (1):65-74. https://doi.org/10.2307/3546547

Noy, C. 2008. Sampling knowledge: the hermeneutics of snowball sampling in qualitative research. International Journal of Social Research Methodology 11(4):327-344. https://doi. org/10.1080/13645570701401305

Ostrom, E. 2007. A diagnostic approach for going beyond panaceas. Proceedings of the National Academy of Sciences of the United States of America 104(39):15181-15187. https://doi. org/10.1073/pnas.0702288104 
Ostrom, E. 2009. A general framework for analyzing sustainability of social-ecological systems. Science 325 (5939):419-422. https://doi.org/10.1126/science.1172133

Peluso, N. L., and J. Ribot. 2020. Postscript: a theory of access revisited. Society and Natural Resources 33(2):300-306. https:// doi.org/10.1080/08941920.2019.1709929

Perrings, C. 1994. Sustainable livelihoods and environmentally sound technology. International Labour Review 133(3):305-326.

Pretty, J. 2011. Interdisciplinary progress in approaches to address social-ecological and ecocultural systems. Environmental Conservation 38(2):127-139. https://doi.org/10.1017/S0376892910000937

Prokopy, L. S., K. Floress, J. G. Arbuckle, S. P. Church, F. R. Eanes, Y. Gao, B. M. Gramig, P. Ranjan, and A. S. Singh. 2019. Adoption of agricultural conservation practices in the United States: evidence from 35 years of quantitative literature. Journal of Soil and Water Conservation 74(5):520-534. https://doi. org/10.2489/jswc.74.5.520

R Core Team. 2019. R: A language and environment for statistical computing. R Foundation for Statistical Computing, Vienna, Austria.

Resnik, J., G. Wallace, M. Brunson, and J. Mitchell. 2006. Open spaces, working places: local government programs can slow loss of rangelands - but only if urban and ranching interests find ways to work together. Rangelands 28(5):4-9. https://doi.org/10.2111/1551-501X (2006)28[4:OSWP] 2.0.CO;2

Ribot, J. C., and N. L. Peluso. 2003. A theory of access. Rural Sociology 68(2):153-181. https://doi.org/10.1111/j.1549-0831.2003. tb00133.x

Saunders, B., J. Sim, T. Kingstone, S. Baker, J. Waterfield, B. Bartlam, H. Burroughs, and C. Jinks. 2018. Saturation in qualitative research: exploring its conceptualization and operationalization. Quality \& Quantity 52(4):1893-1907. https:// doi.org/10.1007/s11135-017-0574-8

Savory, A., and J. Butterfield. 2016. Holistic management - a commonsense revolution to restore our environment. Third edition. Island, Washington, D.C., USA.

Sayer, A. 1979. Epistemology and conceptions of people and nature in geography. Qualitative Change in Human Geography 10(1):19-44. https://doi.org/10.1016/B978-0-08-025222-3.50006-2

Sayre, N. F., L. Carlisle, L. Huntsinger, G. Fisher, and A. Shattuck. 2012. The role of rangelands in diversified farming systems: innovations, obstacles, and opportunities in the USA. Ecology and Society 17(4):43. https://doi.org/10.5751/ES-04790-170443

Sayre, N. F., R. R. McAllister, B. T. Bestelmeyer, M. Moritz, and M. D. Turner. 2013. Earth stewardship of rangelands: coping with ecological, economic, and political marginality. Frontiers in Ecology and the Environment 11(7):348-354. https://doi. org/10.1890/120333

Schlüter, M., B. Müller, and K. Frank. 2019. The potential of models and modeling for social-ecological systems research: the reference from ModSES. Ecology and Society 24(1):31. https:// doi.org/10.5751/ES-10716-240131
Scholte, S. S. K., A. J. A. van Teeffelen, and P. H. Verburg. 2015. Integrating socio-cultural perspectives into ecosystem service valuation: a review of concepts and methods. Ecological Economics 114:67-78. https://doi.org/10.1016/j.ecolecon.2015.03.007

Scoones, I. 1998. Sustainable rural livelihoods: a framework for analysis. IDS Working Paper. Institute of Development Studies, Brighton, UK.

Smith, A., and A. Stirling. 2010. The politics of social-ecological resilience and sustainable socio-technical transitions. Ecology and Society 15(1):11. https://doi.org/10.5751/ES-03218-150111

Solesbury, W. 2003. Sustainable livelihoods: a case study of the evolution of DFID policy. Overseas Development Institute, London, UK.

Sprague, J. 2016. Feminist methodologies for critical researchers: bridging differences. Rowman \& Littlefield, Walnut Creek, California, USA.

Steedman, R. J., and H. A. Regier. 1987. Ecosystem science for the Great Lakes: perspectives on degradative and rehabilitative transformations. Canadian Journal of Fisheries and Aquatic Sciences 44(S2):95-103. https://doi.org/10.1139/f87-313

Stojanovic, T., H. M. McNae, P. Tett, T. W. Potts, J. Reis, H. D. Smith, and I. Dillingham. 2016. The "social" aspect of socialecological systems: a critique of analytical frameworks and findings from a multisite study of coastal sustainability. Ecology and Society 21(3):15. https://doi.org/10.5751/ES-08633-210315

Strauss, A., and J. Corbin. 1994. Grounded theory methodology: an overview. Pages 273-285 in N. K. Denzin and Y. S. Lincoln, editors. Handbook of qualitative research. SAGE, Newbury Park, California, USA.

Strauss, A., and J. Corbin. 1998. Basics of qualitative research. Second edition. SAGE, Thousand Oaks, California, USA.

Topp, C. W., S. D. Østergaard, S. Søndergaard, and P. Bech. 2015. The WHO-5 well-being index: a systematic review of the literature. Psychotherapy and Psychosomatics 84(3):167-176. https://doi.org/10.1159/000376585

Turner II, B. L., R. E. Kasperson, W. B. Meyer, K. M. Dow, D. Golding, J. X. Kasperson, R. C. Mitchell, and S. J. Ratick. 1990. Two types of global environmental change: definitional and spatial-scale issues in their human dimensions. Global Environmental Change 1(1):14-22. https://doi.org/10.1016/0959-3780 (90)90004-S

U.S. Census Bureau. 2000. Census of population and housing. United States Census Bureau, Washington, D.C., USA.

U.S. Census Bureau. 2010. Census of population and housing. United States Census Bureau, Washington, D.C., USA.

U.S. Department of Agriculture National Agricultural Statistics Service (USDA NASS). 2017. Census of agriculture. USDA NASS, Washington, D.C., USA.

Vitiello, D., and L. Wolf-Powers. 2014. Growing food to grow cities? The potential of agriculture for economic and community development in the urban United States. Community Development Journal 49(4):508-523. https://doi.org/10.1093/cdj/ bst087 
Wells, B. L. 1998. Creating a public space for women in US agriculture: empowerment, organization and social change. Sociologia Ruralis 38(3):371-390. https://doi.org/10.1111/1467-9523.00084

Welsh, M. 2014. Resilience and responsibility: governing uncertainty in a complex world. Geographical Journal 180 (1):15-26. https://doi.org/10.1111/geoj.12012

Westley, F., P. Olsson, C. Folke, T. Homer-Dixon, H. Vredenburg, D. Loorbach, J. Thompson, M. Nilsson, E. Lambin, J. Sendzimir, B. Banerjee, V. Galaz, and S. van der Leeuw. 2011. Tipping toward sustainability: emerging pathways of transformation. Ambio 40:762. https://doi.org/10.1007/s13280-011-0186-9

Westley, F. R., O. Tjornbo, L. Schultz, P. Olsson, C. Folke, B. Crona, and Ö. Bodin. 2013. A theory of transformative agency in linked social-ecological systems. Ecology and Society 18(3):27. https://doi.org/10.5751/ES-05072-180327

Wilmer, H., M. E. Fernández-Giménez, S. Ghajar, P. L. Taylor, C. Souza, and J. D. Derner. 2020. Managing for the middle: rancher care ethics under uncertainty on Western Great Plains rangelands. Agriculture and Human Values 37:699-718. https:// doi.org/10.1007/s10460-019-10003-W

Wongbusarakum, S., E. M. Madeira, and H. Hartanto. 2014. Strengthening the social impacts of sustainable landscapes programs. The Nature Conservancy, Arlington, Virginia, USA.

Woodhouse, E., K. M. Homewood, E. Beauchamp, T. Clements, J. T. McCabe, D. Wilkie, and E. J. Milner-Gulland. 2015. Guiding principles for evaluating the impacts of conservation interventions on human well-being. Philosophical Transactions of the Royal Society B 370(1681). https://doi.org/10.1098/ rstb.2015.0103

Woodhouse, E., and J. T. McCabe. 2018. Well-being and conservation: diversity and change in visions of a good life among the Maasai of northern Tanzania. Ecology and Society 23(1):43. https://doi.org/10.5751/ES-09986-230143

York, A. M., M. Shrestha, C. G. Boone, S. Zhang, J. A. Harrington, T. J. Prebyl, A. Swann, M. Agar, M. F. Antolin, B. Nolen, J. B. Wright, and R. Skaggs. 2011. Land fragmentation under rapid urbanization: a cross-site analysis of Southwestern cities. Urban Ecosystems 14(3):429-455. https://doi.org/10.1007/ s11252-011-0157-8 
Appendix 1. The semi-structured interview script. Throughout the research process, we adapted the interview questions with the below script reflecting all included questions.

Hello. My name is Anonymous Author, and I am a Title from Institution and Department. We are conducting a research study on the experiences of ranchers and farmers in the United States (U.S.) West. I have come here to ask you some questions related to your experiences of ranching and farming. The information you provide is confidential. This means that we will not publish your name or any personal information. The interview will take approximately 2 hours, and you can end the interview at any time. Do you mind if I take notes and audio-record while we talk? If you have any questions, don't hesitate to ask. Also, your participation is voluntary.

\section{Identity}

- First, what is your name and the name of your ranch/farm/operation?

- Do you yourself identify as a rancher, farmer, business/agribusiness operator, etc.?

- I am interested in the experiences of a range of producers from farmers to ranchers to agribusiness operators, and more specifically, I am interested to understand the unique roles of each of these operators. I noticed that you identified your operation as a [select title]. What does it mean to be [select title] operation versus a [select title]?

- What does it mean to be a [selected title], and how is a [select title] different from a [select title]?

- How many years have you been a [selected title], and where your parents [select title]? Note: If prompted by the participant, a lengthier discussion of family history may develop. If not, this discussion will be continued below with questions regarding succession.

\section{Land Use}

- Can you describe your operation to me? Note: Depending upon what the individual mentions, may follow-up with some more specific questions regarding scale?

- (If not mentioned above) What type of operation do you run, and what livestock are involved in the operation? Note: Depending upon the response of the individual, I will follow-up with questions regarding breeds, breed selection, and potentially, scale?

- In addition to livestock production, are you involved in other enterprises (e.g., hay production, tourism, construction, etc.)?

\section{Livelihoods}

- Have you experience a major event such as drought? If yes, can you walk me through the experience?

If yes and after the initial overview, we will address the below matrix:

1. Event

2. Did you have a plan in-place for the event? If yes, was it useful?

3. Effect of the event

4. Your Response

5. Community Response

6. Who was Affected within the household? How?

7. Who was Affected within the community? How? 
8. What were some sources of support? Note: If only income-based support is mentioned, I will inquire more broadly regarding support (e.g., family, church, academic institution)?

Note: If an event(s) is identified, this will prompt discussion on the role of community and individuals in livelihood coping strategies.

- How has this experience changed you and your operation?

- Is there anything important about the drought event that I forgot to ask about?

\section{Change}

- What are the main things that have been changing in this community over the past five years or so? Has the economic base changed (e.g., from agriculture to oil \& gas or to tourism)?

- Are the kinds of people who live in the community change and if so how? Is the population size changing? If yes, why are people migrating in and out of the community? Why have you remained in the community?

- (If not discussed in the Individual/identity section above) How did you become a [select title]?

- Do you have a person or institution to continue the operation of your ranch or farm once you retire? If so, who, and how did you establish the relationship with this individual?

- People have told me that ranching, farming, or more generally, a rural lifestyle can be in our DNA, passed down and maintained? How do you think ranching/farming/rural lifestyles could be maintained in the US? What do you see as the future of ranching/farming/rural lifestyles in the US?

\section{Well-being and Gender}

- In your experience, have you observed or experienced negative changes to ranching/farming in the last five years? Last 10 years? Have these changes impacted your life in the last five years? Last 10 years?

- In your experience, have you observed or experienced positive changes to ranching/farming in the last five years? Last 10 years? Have these changes impacted your life in the last five years? Last 10 years?

- More specifically, what have been the main challenges for you and your operation over the past five years (e.g., labor shortage, marketing, production, etc.)? Last 10 years?

- Has your access to natural resources changed over the past 10 years (e.g., access to land, water, etc.)?

- Have you seen changes in the roles of men and women over the past five, 10 years, and across the last few generations? If yes, can you describe some of these changes? How have you seen the lives of women improved, and how have women become more disadvantaged? How have the lives of men improved, and how have men become more disadvantaged?

- Have you observed that certain individuals or groups of people are excluded from the benefits of the ranching/farming lifestyle? If so which group or groups of people? Have you observed that certain individuals or groups of people have recently been welcomed into the ranching/farming lifestyle? If so, which group or groups of people?

- Are there organizations or institutions have held you back from gaining a better living? Are there people in the community who are particularly disadvantaged by the way these organizations or institutions work? If so, which group or groups of people? Inversely, are 
there organizations or institutions have helped you to gain a better living? If yes, how have they supported you?

- What changes would you like to make to your lifestyle or operation? What has held you back from making these changes? What are some opportunities that may help you achieve your desired goals?

\section{Wrap-up}

- Is there any question or questions that you would like to ask me?

- Is there anything that I missed or should have asked? 